\title{
Longitudinal study of Clostridium difficile shedding in raccoons on swine farms and conservation areas in Ontario, Canada
}

\author{
Kristin J. Bondo ${ }^{1}$, J. Scott Weese ${ }^{1}$, Joyce Rouseau ${ }^{1}$ and Claire M. Jardine ${ }^{2^{*}}$
}

\begin{abstract}
Background: Clostridium difficile is an important enteropathogen affecting humans, domestic animals, and wildlife. The objectives of this study were to 1) compare the prevalence and characteristics of $C$. difficile isolated from the feces of raccoons trapped on swine farms and conservation sites, and 2) investigate the role of raccoons as potential reservoirs for host-adapted strains of $C$. difficile using a longitudinal study. Fecal swabs were collected from raccoons at 5 conservation sites and 5 swine farms, once every five weeks, from May to November, 2012.

Results: Clostridium difficile was isolated from $9 \%$ (38/444) of samples, from $12 \%$ (37/302) of raccoons, from all 10 sites. A total of 19 different ribotypes were identified, including 5 ribotypes that matched recognized international designations and which are also found in humans $(001,014,056,078$, and 103). Location type (farm or conservation area) was not associated with $C$. difficile status $(P=0.448)$ but only 3 ribotypes $(014,056$, and 078$)$ were found in both location types. The prevalence of ribotype 078 was significantly higher on farms (4 \%; 9/220) compared to conservation sites $(1 \% ; 2 / 225)(P=0.034)$. Only one of 108 raccoons caught in multiple sessions was positive on more than one occasion.

Conclusions: We found no evidence to support the hypothesis that raccoons harbour host-adapted strains of C. difficile; rather, it appears that raccoons transiently acquire C. difficile from the environment. Raccoons are unlikely to be maintaining $C$. difficile, but because we detected $C$. difficile strains that have the potential to cause illness in humans and livestock, and because raccoons can move relatively large distances, they may play a role in the dissemination of pathogenic ribotypes of $C$. difficile throughout the environment.
\end{abstract}

Keywords: Clostridium difficile, Conservation area, Longitudinal study, Procyon lotor, Raccoon, Swine farm

\section{Background}

Clostridium difficile is an anaerobic bacterium that is an important enteropathogen in humans and some domestic animals $[1,2]$. Clostridium difficle is one of the top 5 infectious causes of human mortality in Ontario, responsible for 327 deaths annually [3]. In addition to humans and domestic animals, disease associated with $C$. difficile has been reported in a variety of wildlife species $[4,5]$. Clostridium difficile can also be found in soil and water and in the intestinal tracts of apparently healthy humans and animals, including wildlife [6-8]. Although wild animals are reservoirs for various infectious agents and can

\footnotetext{
* Correspondence: cjardi01@uoguelph.ca

${ }^{2}$ Department of Pathobiology and Canadian Wildlife Health Cooperative, University of Guelph, Guelph, ON N1G 2W1, Canada

Full list of author information is available at the end of the article
}

be involved in the transmission of pathogens to and from humans and domestic animals [9], the role of wildlife, if any, in the epidemiology of $C$. difficile is not clear [10].

Raccoons are commonly found in close association with humans and domestic animals. They are known to harbour a number of zoonotic pathogens, including $C$. difficile and in a previous study of raccoons trapped on farms, four unique $C$. difficile isolates were identified, none of which were present in the authors' reference library of over 3,000 human and domestic animal C. difficile isolates [10]. Based on these findings, we hypothesized that raccoons may carry host-adapted strains of $C$. difficile that are unrelated to direct or indirect (e.g., environmental) exposure from humans or domestic animals. The objectives of this study were to 1) compare the prevalence 
and characteristics of $C$. difficile isolated from the feces of raccoons living on swine farms and conservation areas (areas with no exposure to livestock), 2) assess the impact of location type (farm versus conservation area), raccoon demographic factors, and season on the prevalence of $C$. difficile in raccoons, and 3) investigate the role of raccoons as potential maintenance hosts of host adapted strains of C. difficile using a longitudinal study.

\section{Methods}

Procedures for trapping and handling animals were approved by the Animal Care Committee at the University of Guelph following the guidelines of the Canadian Committee on Animal Care. Raccoons were live-trapped on 5 swine farms and 5 conservation areas in southern Ontario within a $100-\mathrm{km}$ radius of either Guelph $\left(43^{\circ}\right.$

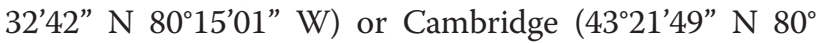
18 '50" W) Ontario from May to October in 2012. Distance between sites ranged from 1.3 to $52.2 \mathrm{~km}$.

At each site, 20-40 Tomahawk live traps were set for 3-4 nights once every 4-5 weeks (Sizes 106 and 108; Tomahawk Live Trap Co. Tomahawk, Wisconsin, USA). Captured raccoons were brought to a centralized holding area for processing unless they had already been caught that week, in which case they were released immediately. Raccoons were anesthetized using an intramuscular injection of $0.025 \mathrm{mg} / \mathrm{kg}$ dexmedetomidine hydrochloride (Dexdomitor $0.5 \mathrm{mg} / \mathrm{ml}$; Pfizer Animal Health, Kirkland, Quebec, Canada) and $5 \mathrm{mg} / \mathrm{kg}$ ketamine hydrochloride (Vetalar $100 \mathrm{mg} / \mathrm{ml}$; Bioniche Animal Health, Belleville, ON, Canada) before being removed from the trap. A numbered metal ear tag (1005-3, National Band and Tag Co. Newport, Kentucky, USA) was placed in one ear and a passive integrated transponder tag (GPT12 Pre-Load Sterile; Biomark, Boise, Idaho, USA) was injected subcutaneously between the shoulder blades for subsequent identification. Sex, age class (adult or juvenile, on the basis of animal size and teeth wear and staining), and mass were recorded for each animal. Fecal swabs were collected per rectum using Cary-Blair applicators (BBL CultureSwab, Becton, Dickinson and Company, Annapolis, Maryland, USA) and then refrigerated.

To isolate $C$. difficile, swabs were immersed in $C$. difficile moxalactam-norfloxacin (CDMN) broth (Oxoid Ltd., Nepean, ON, Canada) with $0.1 \%$ taurocholate and incubated anaerobically at $37^{\circ} \mathrm{C}$. After 7 days, alcohol shock was performed by mixing $2 \mathrm{ml}$ of broth with $2 \mathrm{ml}$ absolute ethanol. After $1 \mathrm{~h}$ incubation at room temperature, samples were centrifuged and the pellet was inoculated onto CDMN agar for anaerobic incubation for $48 \mathrm{~h}$. Clostridium difficile was tentatively identified by colony morphology, Gram stain appearance and l-proline aminopeptidase production. A single isolate from each sample was characterized by ribotyping [11], PCR detection of tcdA, tcdB and $\operatorname{cdtA} / \mathrm{cdtB}$ [12], and toxinotyping [13]. Isolates that visually matched ribotype patterns of reference strains from the Cardiff/ECDC reference collection were assigned the corresponding designation (e.g., 078). Otherwise, isolates were compared to an internal collection.

Logistic regression models with random effects were constructed in STATA (STATA Intercooled 13.1; StataCorp, College Station, Texas, USA) to examine associations between the presence of $C$. difficile and four variables: location type (conservation area or swine farm), season (late May-July or August-October), age (juvenile or adult), and sex (male or female). Two distinct seasons were considered: rearing (May-July) and pre-denning/dispersal (August-October) as defined by Rosatte et al. (2010) [14]. Random effects for site and animal were included to account for autocorrelation among samples taken from the same site and the same animal. Univariable models, i.e., one fixed effect per model, were initially created with random effects and then multivariable models that included interaction terms, main and random effects were built. In creating multivariable models, a main effects model was initially constructed, variables that were not statistically significant were removed assuming they were not potential confounding variables, and then all possible interactions were individually examined. Variables were retained in the final model if they were significant, part of a significant interaction term or acted as a confounding variable. A variable was considered to be a confounding variable if it was a nonintervening variable and its removal from the model resulted in $\geq 30 \%$ change in any of the coefficients of a statistically significant variable [15]. Variance partition coefficients (VPCs) were estimated from the variance components of the final model including both fixed and random effects using the latent variable technique [15]. Random effects were excluded from models if their inclusion explained very little of the variation and if excluding them resulted in a model with a better fit or no change based on Akaike's Information Criterion (AIC) and Bayesian Information Criterion (BIC) [15]. Odds ratio and $95 \%$ confidence interval $(\mathrm{CI})$ of each variable were reported.

Due to small sample sizes, exact logistic regression was used to compare the prevalence of specific ribotypes of $C$. difficile between the conservation and farms sites. Associations for all statistical tests were considered significant at $\alpha=0.05$.

\section{Results}

Clostridium difficile was isolated from 8.6 \% (95 \% CI, 6.1-11.6 \%; 38/444) of samples from $12.3 \%$ (95\% CI, 8.8-16.5\%; 37/302) of raccoons from all 10 locations. Only one of 108 raccoons caught in multiple sessions was positive at more than one time. Samples from this 
raccoon were collected 8 weeks apart, and different ribotypes were found at each sampling period. Of the 108 recaptures, 83 occurred in consecutive months. Seventytwo of these raccoons were negative on all captures, 3 were negative on one occurrence and positive on subsequent capture (4-5 weeks later), and 8 were positive on one occurrence and negative upon a subsequent capture. One adult male raccoon was caught at two different swine farms (1.3 km apart), so one of the results from this animal was randomly removed from the statistical analysis.

In the univariable models, $C$. difficile was more likely to be detected in raccoons sampled in May-July than in August-October and more likely to be detected in adult than juvenile raccoons (Table 2). The final model included only season because in the multivariable logistic regression model, season remained significant $(\mathrm{OR}=$ 3.78; $95 \% \mathrm{CI}, 0.094-0.74, P=0.011$ ), but age was no longer significant because season confounded age $(\mathrm{OR}=$ 2.55; $95 \% \mathrm{CI}, 1.36-10.58, P=0.231)$. In addition, when the other variables were included together in the model with season, none of the other variables were confounding variables, and there were no significant interactions. Based on the estimates of the VPCs, site and sample level (i.e., swab tested) explained $9.1 \%$ and $90.9 \%$, respectively, of the variance in $C$. difficile occurrence in the model with season (Table 2).

Of the 38 isolates, 20 (52.6 \%; $95 \%$ CI, 35.8-69.0\%) had $t c d A$ and $t c B$, but not $c d t A, 14(36.8 \% ; 95 \% \mathrm{CI}$, $21.8-54.0 \%)$ had all three genes and 4 (10.5\%; $95 \% \mathrm{CI}$, $2.9-24.8 \%$ ) had no toxin genes (Table 1). A total of 19 different ribotypes were identified, including 5 ribotypes that matched recognized international designations, 4 that matched previously identified ribotypes in our laboratory (including four that have been previously identified in humans and 1 that was detected in a raccoon in 2010 ), and 10 that have not been previously identified in our laboratory. Overall, 28/34 (82 \%; 95 \% CI, 65.5$93.2 \%)$ toxigenic isolates were ribotypes that have been previously identified in humans by this laboratory while 6/34 (18 \%; $95 \%$ CI, 6.8-34.5\%) were strains that have only been identified by this laboratory in raccoons.

Location type (farm or conservation area) was not associated with $C$. difficile status $(P=0.448$; Table 2$)$, but $9 / 19$ ribotypes were found only on farms and 7/19 ribotypes were found only in conservation areas (Table 1 ). Only 3 ribotypes $(014,056$, and 078$)$ were found in both location types (Table 1). The prevalence of ribotype 078

Table 1 Relative frequencies of Clostridium difficile ribotypes (with toxin profile and toxinotype) isolated from raccoons trapped on farms and conservation areas in Ontario, Canada

\begin{tabular}{|c|c|c|c|c|c|}
\hline Ribotype $^{a}$ & Toxin gene(s) & Toxinotype & $\begin{array}{l}\text { No. }(\%) \text { of isolates } \\
\text { from farms } \\
n=219\end{array}$ & $\begin{array}{l}\text { No. (\%) of isolates } \\
\text { conservation from areas } \\
n=225\end{array}$ & $\begin{array}{l}\text { Total no. (\%) } \\
\text { isolates } \\
n=444\end{array}$ \\
\hline 001 & $\mathrm{~A}+\mathrm{B}+\mathrm{CDT}-$ & 0 & 0 & 2 (0.9 \%) & $2(0.4 \%)$ \\
\hline 014 & $\mathrm{~A}+\mathrm{B}+\mathrm{CDT}-$ & 0 & 2 (0.9 \%) & $4(1.8 \%)$ & $6(1.3 \%)$ \\
\hline 056 & $\mathrm{~A}+\mathrm{B}+\mathrm{CDT}-$ & $X \|$ & 2 (0.9 \%) & 1 (0.4 \%) & $3(0.7 \%)$ \\
\hline 078 & $\mathrm{~A}+\mathrm{B}+\mathrm{CDT}+$ & V & $9(4.1 \%)$ & $2(0.9 \%)$ & $11(2.5 \%)$ \\
\hline 103 & $\mathrm{~A}+\mathrm{B}+\mathrm{CDT}-$ & $\|$ & 0 & $1(0.4 \%)$ & $1(0.2 \%)$ \\
\hline AG & $\mathrm{A}+\mathrm{B}+\mathrm{CDT}-$ & 0 & 0 & $1(0.4 \%)$ & $1(0.2 \%)$ \\
\hline $\mathrm{F}$ & $\mathrm{A}+\mathrm{B}+\mathrm{CDT}-$ & 0 & $1(0.5 \%)$ & 0 & $1(0.2 \%)$ \\
\hline । & $\mathrm{A}+\mathrm{B}+\mathrm{CDT}-$ & 0 & 0 & 2 (0.9 \%) & $2(0.4 \%)$ \\
\hline O & $\mathrm{A}+\mathrm{B}+\mathrm{CDT}-$ & 0 & 0 & 1 (0.4 \%) & 1 (0.2 \%) \\
\hline WR10 & A-B-CDT- & NA & $1(0.5 \%)$ & 0 & $1(0.2 \%)$ \\
\hline WR12 & $\mathrm{A}+\mathrm{B}+\mathrm{CDT}+$ & V & 0 & $1(0.4 \%)$ & $1(0.2 \%)$ \\
\hline WR13 & $\mathrm{A}+\mathrm{B}+\mathrm{CDT}-$ & 0 & $1(0.5 \%)$ & 0 & $1(0.2 \%)$ \\
\hline WR3 & $\mathrm{A}+\mathrm{B}+\mathrm{CDT}+$ & IV & $1(0.5 \%)$ & 0 & $1(0.2 \%)$ \\
\hline WR4 & $\mathrm{A}+\mathrm{B}+\mathrm{CDT}+$ & III & $1(0.5 \%)$ & 0 & 1 (0.2 \%) \\
\hline WR5 & $\mathrm{A}+\mathrm{B}+\mathrm{CDT}-$ & 0 & $1(0.5 \%)$ & 0 & $1(0.2 \%)$ \\
\hline WR6 & A-B-CDT- & NA & $1(0.5 \%)$ & 0 & 1 (0.2 \%) \\
\hline WR7 & A-B-CDT- & NA & 0 & $1(0.4 \%)$ & $1(0.2 \%)$ \\
\hline WR8 & A-B-CDT- & NA & $1(0.5 \%)$ & 0 & $1(0.2 \%)$ \\
\hline WR9 & $\mathrm{A}+\mathrm{B}+\mathrm{CDT}-$ & 0 & $1(0.5 \%)$ & 0 & 1 (0.2 \%) \\
\hline
\end{tabular}

${ }^{a}$ Numerical identifiers match international designations, letter identifiers were assigned to ribotypes previously detected in our laboratory, and WR numbers were assigned to ribotypes that have not been previously identified in our laboratory or that have only been see in wildlife (i.e., WR3 which was detected in a raccoon in 2010) 
Table 2 Univariable logistic regression model with random effects (site and animal) showing associations between Clostridium difficile status and raccoon age (adult or juvenile), sex, location type (farm or conservation area), and season (May to July or August to October)

\begin{tabular}{|c|c|c|c|c|c|c|c|}
\hline \multirow[t]{3}{*}{ Predictor } & \multirow[t]{3}{*}{ Sub-category ( $n=$ sample size) } & \multirow{3}{*}{$\begin{array}{l}\text { \% C. difficile positive } \\
(95 \% \text { Cl) }\end{array}$} & \multicolumn{5}{|c|}{ Univariable models ${ }^{\mathrm{b}}$} \\
\hline & & & \multirow[t]{2}{*}{ Odds ratio } & \multirow[t]{2}{*}{$95 \% \mathrm{Cl}$} & \multicolumn{2}{|c|}{ Covariance parameter estimates (95 \% Cl) } & \multirow[t]{2}{*}{$P$} \\
\hline & & & & & Site level & Animal level $^{d}$ & \\
\hline \multirow[t]{2}{*}{$\overline{\mathrm{Age}^{c}}$} & Juvenile $(n=83)$ & $2.4(0.3-8.4)$ & Referent & & & & \\
\hline & Adult $(n=360)$ & $10.0(7.1-13.6)$ & 4.79 & $1.11-20.60$ & $0.28(0.04-1.8)$ & & 0.036 \\
\hline \multirow[t]{2}{*}{ Location type } & Conservation $(n=225)$ & $7.1(4.1-11.3)$ & Referent & & & & \\
\hline & Swine farm $(n=219)$ & $10.0(6.4-14.8)$ & 1.42 & $0.57-3.59$ & $0.21(0.02-1.8)$ & & 0.448 \\
\hline \multirow[t]{2}{*}{ Sex } & Female $(n=245)$ & $8.6(5.4-12.8)$ & Referent & & & & \\
\hline & Male $(n=199)$ & $8.5(5.1-13.3)$ & 0.93 & $0.46-1.88$ & $0.27(0.04-1.9)$ & $0.14^{e}$ & 0.831 \\
\hline \multirow[t]{2}{*}{ Season } & Aug. to Oct. $(n=165)$ & $3.0(1.0-6.9)$ & Referent & & & & \\
\hline & May to July ( $n=279$ ) & $11.8(8.3-16.2)$ & 4.81 & $1.80-12.87$ & $0.21(0.06-1.8)$ & & 0.002 \\
\hline
\end{tabular}

${ }^{\mathrm{a}} \mathrm{Cl}=$ confidence interval

${ }^{\mathrm{b}}$ Significant differences are in bold

${ }^{\mathrm{c}}$ Age for 1 individual was unknown

${ }^{\mathrm{d}}$ The random effect for animal was not included in the models for age, location type, and season because it explained $5.3 \times 10^{-31}$ to $4.2 \times 10^{-30}$ of the variance, and its removal from the model changed the coefficients little and did not change the model according to AIC and BIC

${ }^{\text {e}}$ The $95 \%$ confidence interval was estimated to be between $3.6 \times 10^{-11}$ and $5.6 \times 10^{8}$

was significantly higher on farms $(9 / 219)$ compared to conservation sites $(2 / 225)(\mathrm{OR}=4.8 ; 95 \% \mathrm{CI}, 0.97-45.8$; $P=0.034)$, but there was no significant difference in prevalence of ribotype $056(\mathrm{OR}=2.1 ; 95 \% \mathrm{CI}, 0.11$ $122.3 ; P=0.619)$ or ribotype $014 \quad(\mathrm{OR}=51 ; 95 \% \mathrm{CI}$, $0.04-3.6 ; P=0.686$ ) between location types.

\section{Discussion}

The prevalence of $C$. difficile in fecal samples from raccoons in this study (9\%) was similar to what was detected in a previous study of raccoons in Ontario (8\%) [10]; however, we detected $C$. difficile in raccoons at all sites sampled in this more recent study and only at $16 \%$ of farm sites in 2010. We also detected a greater variety of ribotypes, including ribotypes that are known to be associated with human and livestock disease, compared to the previous study by Jardine et al. (2013) [10]. The greater sample size used in the current study may be responsible for the observed higher site prevalence and greater ribotype diversity of $C$. difficile, but it is also possible that different ribotypes have emerged in raccoons since 2010 [10].

In contrast to the previous study by Jardine et al. (2013) [10], five internationally recognized C. difficile ribotypes that are known to be associated with disease in humans and/or livestock were detected in raccoons in this study. These included ribotypes 001, 014, and 078, which were the top three ribotypes detected in samples from hospitalized patients in the Netherlands in 2009 [16] and among the top 11 ribotypes detected in symptomatic patients in North America [17]. Although these ribotypes are also commonly detected in livestock and environmental samples [18, 19] transmission between humans, animals and the environment has not been proven [20]. The emergence of ribotype 078, a strain over-represented in community-associated disease in humans in some regions, has been epidemiologically linked to its occurrence in livestock, suggesting that there is at least the potential for zoonotic transmission [20]. The detection of known pathogenic ribotypes of $C$. difficile and isolates with toxin genes $t c d A$ and $t c B$, which are known to be associated with human disease, in raccoons raises concerns about their potential to act as a component of the $C$. difficile reservoir and contribute to the transmission of $C$. difficile to humans [21].

In our longitudinal study, only one of 108 raccoons caught on multiple occasions tested positive repeatedly for C. difficile, and this individual had different strains of C. difficile at each trapping session. We therefore conclude that $C$. difficile shedding in raccoon feces is transient with raccoons harbouring $C$. difficile for only short periods of time ( $<5$ weeks). A similar pattern of transient $C$. difficile shedding was described in a longitudinal study of healthy horses [22] and dogs [23]. Our conclusions are subject to a couple of caveats. First, because we only tested a single $C$. difficile colony per sample, we could not determine if raccoons were simultaneously colonized with multiple ribotypes. Second, it is not clear if our findings represent intermittent true colonization or detection of ingested spores transiently passing through the intestinal tract [24]. Although further work is required to clarify these aspects of $C$. difficile shedding 
in raccoons, it seems clear that raccoons are unlikely to be maintaining $C$. difficile for any length of time. Although the prevalence of $C$. difficile in raccoons did not differ between location type (farm or conservation area), there was little overlap in strain types between farms and conservation areas. In addition, although ribotype 078 was found on both farms and conservation areas, it was significantly more likely to occur in raccoons trapped on farms than conservation areas. This, combined with the high prevalence of ribotype 078 in some livestock farms [25], suggests that raccoons obtain $C$. difficile as a consequence of environmental exposure and may, therefore, act as sentinels for $C$. difficile in the environment. We were not able to obtain samples from farm animals or the environment for $C$. difficile testing in this study and were unable to factor clustering by site in the statistical analyses comparing prevalence of specific ribotypes between location types because of small effective sample size. Because three of the farms were in close proximity to one another, they may not have been entirely independent units. Further studies with larger sample sizes and more study sites that concurrently examine the occurrence of $C$. difficile in wildlife, livestock and the environment will help to identify potential sources of $C$. difficile for wildlife.

Based on the univariable models, the prevalence of $C$. difficile in raccoons was higher from May to July than from August to October and higher in adults than juveniles; however, in the multivariable model, season confounded age. In humans, Clostridium difficile infections occur more frequently in the winter months [26]; however, we did not sample raccoons in the winter in this study. Himsworth et al. (2014) [27] found no association between season and $C$. difficile status in wild urban rats (Rattus spp). Young age, particularly prior to weaning, is associated with $C$. difficile shedding in several species $[28,29]$. Because all of the raccoons in our study were free-ranging and live-trapped, juveniles we captured were at least in the process of being weaned. In our study, most adults $(72 \%$; $261 / 360)$ were captured during May to July whereas most juveniles (80 \%; 66/83) were captured August to November. This disproportionate number of adults and juveniles captured according to season may have influenced the relationship between age and season in the multivariable model. Additional studies, occurring over longer time periods, with larger sample sizes, and with raccoons prior to weaning are required to better understand the seasonal and demographic factors that may be associated with $C$. difficile occurrence in wildlife.

\section{Conclusions}

We found no evidence to support the hypothesis that raccoons are maintaining host-adapted strains of $C$. difficile; rather, it appears that raccoons transiently acquire $C$. difficile from the environment. We detected $C$. difficile strains in raccoons that have the potential to cause illness in humans and livestock; however, all raccoons sampled for this study appeared clinically normal and there was no apparent impact of $C$. difficile shedding on raccoon health. Although raccoons are unlikely to be maintaining $C$. difficile, they have been observed to move as far as $45 \mathrm{~km}$ in Ontario [14] and may therefore play a role in the dissemination of pathogenic ribotypes of $C$. difficile throughout the environment.

\section{Competing interests}

The authors declare that they have no competing interests.

\section{Authors' contributions}

KJB participated in study design and field work, performed the statistical analysis and helped to draft the manuscript. JSW participated in study design and helped to draft the manuscript. JR conducted the microbial testing and helped to draft the manuscript. CMJ conceived of the study, participated in its design and coordination, and drafted the manuscript. All authors read and approved the final manuscript.

\section{Authors' information}

Not applicable.

\section{Acknowledgements}

We would like to thank Erin Harkness, Samantha Allen, and Samantha Kagan for assisting with field data collection. We would also like to thank Bryan Bloomfield for maintaining relations with landowners, Tami Sauder for submitting lab samples, Quentin Papach for assisting with the development of a Microsoft Access database, and David Pearl for helpful discussions regarding statistical analysis. Funding was provided by the National Science and Engineering Research Council (NSERC). K.B. received an Ontario Graduate Scholarship and support from the United States Department of Agricultural Research (USDA).

\section{Author details}

${ }^{1}$ Department of Pathobiology, University of Guelph, Guelph, Ontario N1G 2W1, Canada. ${ }^{2}$ Department of Pathobiology and Canadian Wildlife Health Cooperative, University of Guelph, Guelph, ON N1G 2W1, Canada.

Received: 8 June 2015 Accepted: 25 September 2015

Published online: 07 October 2015

\section{References}

1. Jhung MA, Thompson AD, Killgore GE, Zukowski WE, Songer G, Warny M, et al. Toxinotype $V$ Clostridium difficile in Humans and Food Animals. Emerg Infect Dis. 2008:14:1039-45.

2. Kwong JC, Ratnasingham S, Campitelli MA, Daneman N, Deeks SL, Manuel $D G$, et al. The impact of infection on population health: results of the Ontario burden of infectious diseases study. PLoS ONE. 2012;7(9):e44103.

3. Marks SL, Kather EJ, Kass PH, Melli AC. Genotypic and phenotypic characterization of Clostridium perfringens and Clostridium difficile in diarrheic and healthy dogs. J Vet Intern Med. 2002;16:533-40.

4. Arroyo LG, Rousseau JD, Staempfli HR, Weese JS. Suspected Clostridium difficile-associated hemorrhagic diarrhea in a 1-week-old elk calf. Can Vet J. 2005;46:1130-31.

5. Silva RO, D'elia ML, de Magalhães Soares DF, Cavalcanti ÁR, Leal RC, Cavalcanti G, et al. Clostridium difficile-associated diarrhea in an ocelot (Leopardus pardalis). Anaerobe. 2013;20:82-4.

6. Al Saif N, Brazier JS. The distribution of Clostridium difficile in the environment of South Wales. J Med Microbiol. 1996;45:133-37.

7. lizuka M, Konno S, Itou H, Chihara J, Toyoshima I, Horie Y, et al. Novel evidence suggesting Clostridium difficile is present in human gut microbiota more frequently than previously suspected. Microbiol Immunol. 2004;48:889-92. 
8. Thakur S, Sandfoss M, Kennedy-Stoskopf S, DePerno CS. Detection of Clostridium difficile and Salmonella in feral swine population in North Carolina. J Wildl Dis. 2011;47:774-76.

9. Daszak P, Cunningham AA, Hyatt AD. Emerging infectious diseases of wildlife-threats to biodiversity and human health. Science. 2000;287:443-49.

10. Jardine CM, Reid-Smith RJ, Rousseau J, Weese JS. Detection of Clostridium difficile in small and medium-sized wild mammals in Southern Ontario, Canada. J Wildl Dis. 2013;49:418-21.

11. Bidet P, Barbut F, Lalande V, Burghoffer B, Petit JC. Development of a new PCR-ribotyping method for Clostridium difficile based on ribosomal RNA gene sequencing. FEMS Microbiol Lett. 1999;175:261-66.

12. Persson $\mathrm{S}$, Torpdahl M, Olsen KEP. New multiplex PCR method for the detection of Clostridium difficile toxin $A(t c d A)$ and toxin $B(t c d B)$ and the binary toxin (cdtA / cdtB) genes applied to a Danish strain collection. Clin Microbiol Infect. 2008;14:1057-64.

13. Rupnik M, Avesani V, Janc M, von Eichel-Streiber C, Delmée M. A novel toxinotyping scheme and correlation of toxinotypes with serogroups of Clostridium difficile isolates. J Clin Microbiol. 1998;36:2240-47.

14. Rosatte R, Ryckman M, Ing K, Proceviat S, Allan M, Bruce L, et al. Density, movements, and survival of raccoons in Ontario, Canada: implications for disease spread and management. J Mammal. 2010;91:122-35.

15. Dohoo I, Martin W, Stryhn H. Mixed models for discrete data. In: Veterinary Epidemiologic Research. 2nd ed. Charlottetown: VER Inc; 2009. p. 579-606.

16. Hensgens MP, Goorhuis A, Notermans DW, van Benthem BH, Kuijper EJ. Decrease of hypervirulent Clostridium difficile PCR ribotype 027 in the Netherlands. Euro Surveill. 2009;12:14(45).

17. Tickler IA, Goering RV, Whitmore JD, Lynn AN, Persing DH, Tenover FC. Healthcare Associated Infection Consortium. Strain types and antimicrobial resistance patterns of Clostridium difficile isolates from the United States, 2011 to 2013. Antimicrob Agents Chemother. 2014;58:4214-18.

18. Keessen EC, Gaastra W, Lipman LJ. Clostridium difficile infection in humans and animals, differences and similarities. Vet Microbiol. 2011;153:205-17.

19. Janezic S, Ocepek M, Zidaric V, Rupnik M. Clostridium difficile genotypes other than ribotype 078 that are prevalent among human, animal and environmental isolates. BMC Microbiol. 2012;12:48.

20. Hensgens MP, Keessen EC, Squire MM, Riley TV, Koene MG, de Boer E, et al. European Society of Clinical Microbiology and Infectious Diseases Study Group for Clostridium difficile (ESGCD). Clostridium difficile infection in the community: a zoonotic disease? Clin Microbiol Infect. 2012;18:635-45.

21. Haydon DT, Cleaveland S, Taylor LH, Laurenson MK. Identifying reservoirs of infection: a conceptual and practical challenge. Emerg Infect Dis. 2002;8:1468-73.

22. Schoster A, Staempfli HR, Arroyo LG, Reid-Smith RJ, Janecko N, Shewen PE, et al. Longitudinal study of Clostridium difficile and antimicrobial susceptibility of Escherichia coli in healthy horses in a community setting Vet Microbiol. 2012;159:364-70.

23. Weese JS, Finley R, Reid-Smith R, Janecko N, Rousseau J. Evaluation of Clostridium difficile in dogs and the household environment. Epidemiol Infect. 2010;138:1100-04.

24. Weese JS, Wakeford T, Reid-Smith R, Rousseau J, Friendship R. Longitudinal investigation of Clostridium difficile shedding in piglets. Anaerobe. 2010;16:501-4.

25. Reil M, Hensgens MP, Kuijper EJ, Jakobiak T, Gruber $H$, Kist M, et al. Seasonality of Clostridium difficile infections in Southern Germany. Epidemiol Infect. 2012:140:1787-93.

26. Keel K, Brazier JS, Post KW, Weese S, Songer JG. Prevalence of PCR ribotypes among Clostridium difficile isolates from pigs, calves, and other species. J Clini Microbiol. 2007;45:1963-64.

27. Himsworth CG, Patrick DM, Mak S, Jardine CM, Tang P, Weese JS. Carriage of Clostridium difficile by wild urban Norway rats (Rattus norvegicus) and black rats (Rattus rattus). Appl Environ Microbiol. 2014;80:1299-305.

28. Jangi S, Lamont JT. Asymptomatic colonization by Clostridium difficile in infants: implications for disease in later life. J Pediatr Gastroenterol Nutr. 2010;51:2-7.

29. Norman KN, Harvey RB, Scott HM, Hume ME, Andrews K, Brawley AD. Varied prevalence of Clostridium difficile in an integrated swine operation. Anaerobe. 2009;15:256-60.

\section{Submit your next manuscript to BioMed Central and take full advantage of:}

- Convenient online submission

- Thorough peer review

- No space constraints or color figure charges

- Immediate publication on acceptance

- Inclusion in PubMed, CAS, Scopus and Google Scholar

- Research which is freely available for redistribution

Submit your manuscript at www.biomedcentral.com/submit 